\title{
ABSENCE OF BENEFICIAL EFFECTS FROM INJECTIONS OF DESOXYCORTICOSTERONE ACETATE AND OF CORTICAL ADRENAL EXTRACT IN EXPERIMENTAL ANURIA ${ }^{1}$
}

\author{
By ALEXANDER W. WINKLER, PAUL K. SMITH, AND HEBBEL E. HOFF \\ (From the Department of Internal Medicine and the Laboratories of Pharmacology and \\ Physiology, Yale University School of Medicine, New Haven)
}

(Received for publication February 10, 1942)

Hoff, Smith and Winkler (1) found that dogs with anuria secondary to nephrectomy or to ureteral ligation die from cardiac arrest due to autointoxication with potassium. Potassium, derived from the breakdown of the animal's own tissues, can apparently neither be excreted nor stored, and gradually accumulates until a concentration sufficient to cause cardiac arrest is attained. A clinical state somewhat analogous to these forms of experimental anuria has recently been described by Beall and others $(2,3,4,5)$ in patients with anuria of several days duration following crushing injuries. In some patients the potassium of serum rose considerably, and it seems possible that in some instances death may have been due to potassium poisoning. Since desoxycorticosterone acetate (hereafter called "DOCA") may, under certain circumstances, lower the serum potassium, the possibility that this substance might prove of therapeutic value naturally presented itself. Selye $(6,7)$ and Dosne $(8)$ have in fact reported considerable prolongation of life in anuric rats previously treated with DOCA, and have termed this effect an "antiuremic action." The present study deals mainly with the results of DOCA injections in anuric dogs. Several supplementary experiments with whole cortical extract were carried out.

\section{MATERIALS AND METHODS}

The general procedure and the specific techniques employed have been described in detail previously (1). No water or food was given during the course of the experiments, so that vomiting with secondary chloride depletion was virtually absent. All injections of DOCA or of cortical extract were made after the ureters were ligated.

1 Aided by grants from the Ella Sachs Plotz Fund, the Committee on Therapeutic Research of the American Medical Association, the John and Mary R. Markle Foundation, and the Fluid Research Fund of the Yale School of Medicine.
Fourteen dogs received DOCA intramuscularly or subcutaneously in varying amounts, while four others received cortical extract. Anuria was produced in all instances by ureteral ligation. The course of these injected dogs is compared with that of fifteen dogs in a control series; the protocols of twelve of these have already been published (1). The DOCA was usually dissolved in propylene glycol with gentle warming, injections then being made every twelve to twenty-four hours, in order that some active substance might continually be present. In two experiments the regular commercial preparation of DOCA dissolved in sesame oil was employed.2

\section{RESULTS}

The protocols are summarized in Table I. The times of survival after ligation and the concentrations of potassium in serum at death fall within the same ranges in the injected animals and in those of the control series. The several groups are therefore essentially the same in each of these two respects. Also the increase in serum potassium, relative to the increase in the blood nonprotein nitrogen, is about the same in the control animals and in the injected animals.

Clinically the behavior of the treated animals was indistinguishable from that of the untreated ones. The electrocardiographic changes prior to death in the injected animals were of exactly the same character, typical of progressive potassium poisoning, as those of the control group. The usual relationship of serum potassium to electrocardiographic changes $(1,9)$ was unaltered.

\section{DISCUSSION}

Obviously DOCA had no beneficial effect whatsoever in these animals. Yet DOCA, adminis-

2 Dr. E. Schwenk, of the Research Division of Schering Corporation, generously supplied us with all the desoxycorticosterone acetate used in these studies. Commercial whole adrenal cortical extract (Wilson) was used in three experiments. In a fourth a special adrenal cortical extract prepared by Dr. E. C. Kendall, and kindly furnished to us by him, was employed. 
TABLE I

Summary of results

All injections given after ligation of ureters

\begin{tabular}{|c|c|c|c|c|c|c|}
\hline \multirow{3}{*}{ Num- } & \multirow{2}{*}{ Dose } & \multicolumn{2}{|c|}{ Blood NPN } & \multicolumn{2}{|c|}{$\begin{array}{l}\text { Potassium of } \\
\text { serum }\end{array}$} & \multirow{2}{*}{$\begin{array}{c}\text { Surviva } \\
\text { time }\end{array}$} \\
\hline & & Initial & Death & Initial & Death & \\
\hline & $m g m . .^{1}$ or $c c .^{2}$ & \multicolumn{2}{|c|}{ mgm. per cent } & \multicolumn{2}{|c|}{$m M$. per liter } & hours \\
\hline
\end{tabular}

(A) EXPERTMENTS WITH DESOXYCORTICOSTERONE ACETATE

\begin{tabular}{c|c|c|c|c|c|c}
\hline 1 & $6+10+10$ & 38 & 286 & 6.3 & 13.2 & 90 \\
2 & $10+10+10$ & 29 & 247 & 6.6 & 10.1 & 108 \\
3 & $5+5+5+5$ & 36 & 337 & 5.2 & 14.4 & 102 \\
4 & $25+15$ & 33 & 282 & 4.3 & 12.0 & 66 \\
5 & $50+25$ & 33 & 222 & 4.3 & 10.2 & 47 \\
6 & $50+25$ & 29 & 291 & 3.7 & 10.8 & 72 \\
7 & $25+25+10+10$ & 41 & 277 & 7.42 & 10.6 & 77 \\
8 & $25+25+10+10$ & 28 & 242 & 5.4 & 17.7 & 76 \\
94 & $25+25+10+10$ & 106 & 325 & 6.42 & 11.8 & 78 \\
10 & $100+33+35$ & 28 & 335 & 3.2 & 10.7 & 79 \\
11 & $100+33+35$ & 25 & 288 & 3.5 & 11.1 & 90 \\
12 & $100+33+35$ & 29 & 274 & 3.8 & 12.2 & 84 \\
138 & $50+(15 \times 6)$ & 32 & 344 & 4.9 & 11.5 & 86 \\
14 & $50+(15 \times 5)$ & 29 & 250 & 6.2 & 12.5 & 82 \\
\hline
\end{tabular}

(B) EXPERMMENTS WITH CORTICAL EXTRACT (WILSON)

\begin{tabular}{l|c|c|c|c|c|c}
\hline 1 & 90 & & 370 & 5.0 & 10.8 & 114 \\
2 & 90 & 36 & 351 & 4.1 & 16.5 & 96 \\
3 & 70 & 46 & 298 & 4.7 & 13.1 & 72 \\
4 & 100 & 24 & 265 & 4.4 & 12.0 & 77 \\
\hline
\end{tabular}

(C) CONTROL EXPERIMENTS: AVERAGE VALUES FROM FIFTEEN EXPERIMENTS (1)

\begin{tabular}{l|l|l|l|l|l|l}
\hline & none & $30 \pm 4$ & $290 \pm 65$ & $5.4 \pm 0.8$ & $13.8 \pm 2.9$ & $102 \pm 24$ \\
\hline
\end{tabular}

1 Individual figures refer to doses every 12 to 24 hours. $210 \mathrm{cc}$. every 12 hours.

3 Just after operation.

- Chronic nephritis at autopsy.

$\checkmark$ DOCA in sesame oil.

- Dr. Kendall's extract used.

tered parenterally to the intact animal in doses comparable to those given here, is known to cause an increased renal excretion of potassium (10). In fact, if potassium intake be restricted, DOCA injection in the normal animal will in time deplete the potassium of serum and of muscle as well (11). Since this increased urinary excretion is associated with a diminished concentration of serum potassium, it is not simply a reflection of an extrarenal disturbance of potassium metabolism. A specific effect of DOCA upon the normal kidney therefore seems well established. Our experiments indicate that this renal action is responsible for the main disturbing effect of DOCA upon potassium metabolism, since potassium distribution is not demonstrably affected by it in the anuric animal. Expressed graphically, DOCA injection in the intact animal accelerates the fol- lowing sequence:

$$
\mathrm{K}(\text { Muscle }) \stackrel{(\mathrm{b})}{\longrightarrow} \mathrm{K}(\text { Serum }) \stackrel{(\mathrm{a})}{\longrightarrow} \mathrm{K} \text { (Urine) }
$$

DOCA certainly does act at “(a)." It has, however, been suggested that DOCA and cortical extract may act at "(b)" as well (12). Only some such hypothesis would justify the conclusion that DOCA had a beneficial action in the treatment of anuria. Our experiments do not support the validity of this second supposition.

It is not proper, on the basis of these experiments, to deny extrarenal action of DOCA or of cortical extract upon potassium metabolism. On the contrary, there is good evidence that cortical extracts rich in "compound E" (11 dehydro-17 hydroxy corticosterone) accelerate protein breakdown (13), which in turn might accelerate the release of cellular potassium. Such extracts may also increase glycogen deposition in the liver (14), a process which is thought to be associated with the withdrawal of some potassium from the extracellular fluid (15). All that can be said is that such effects are quantitatively too small to be detected under the conditions of our experiments.

It has been mentioned before that Selye and Dosne $(6,7,8)$ have found that rats previously treated with DOCA survive ureteral ligation for a longer time than do those not so treated. Actually, there is no experimental conflict between their observations and ours. They gave the DOCA injections for a period before the production of the anuria, whereas our injections were always given afterwards. By giving DOCA while the kidneys were still functionally intact, they encouraged an excessive potassium excretion, which might in turn be expected to produce some measure of depletion of tissue potassium (11). Durlacher and Darrow (16) have found that rats depleted of potassium, whether by a low potassium diet or by DOCA administration, will survive longer than control animals, following ureteral ligation. This is presumably due to the presence of an abnormally large potential reservoir in which the potassium, produced by the breakdown of their own tissues after the establishment of anuria, may be stored. A longer time would, therefore, be required for such animals to build up a concentration of potassium in the serum sufficient to bring about cardiac arrest. The prac- 
tical therapeutic possibilities inherent in such use of DOCA in "uremia" are obviously very restricted.

\section{SUMMARY AND CONCLUSIONS}

1. In dogs with anuria following ureteral ligation, the subcutaneous or intramuscular injection of desoxycorticosterone acetate and of cortical adrenal extract were completely without beneficial effect.

2. No effect on potassium distribution within the body was detected.

3. Failure to demonstrate such an action of desoxycorticosterone acetate upon potassium distribution in the anuric animal suggests that its effects upon potassium metabolism in the intact animal are secondary to its renal action.

4. On the basis of present knowledge of its pharmacological action, desoxycorticosterone acetate could only be expected to influence the course of an anuric subject favorably if it were given prior to the establishment of anuria.

\section{BIBLIOGRAPHY}

1. Hoff, H. E., Smith, P. K., and Winkler, A. W., The cause of death in experimental anuria. J. Clin. Invest., 1941, 20, 607.

2. Bywaters, E. G. L., and Beall, D., Crush injuries with impairment of renal function. Brit. M. J., 1941, 1, 427.

3. Beall, D., Bywaters, E. G. L., Belsey, R. H. R., and Miles, J. A. R., Crush injury with renal failure. Brit. M. J., 1941, 1, 432.

4. Mayon-White, R., and Solandt, O. M., A case of limb compression ending fatally in uraemia. Brit. M. J., 1941, 1, 434.
5. Editorial: Crush injury and renal function. Brit. $M$. J., 1941, 1, 445.

6. Selye, H., The beneficial action of desoxycorticosterone acetate in uraemia. Canad. Med. Ass. J., 1940, 43, 333.

7. Selye, H., and Nielsen, K., Action of desoxycorticosterone on non-protein nitrogen content of blood during experimental uremia. Proc. Soc. Exper. Biol. and Med., 1941, 46, 541.

8. Dosne, C., The effect of dosage and duration of administration on the anti-uremia effect of desoxycorticosterone. Am. J. Physiol., 1941, 134, 71.

9. Winkler, A. W., Hoff, H. E., and Smith, P. K., Electrocardiographic changes and concentration of potassium in serum following injection of potassium chloride. Am. J. Physiol., 1938, 124, 478.

10. Kuhlmann, D., Ragan, C., Ferrebee, J. W., Atchley, D. W., and Loeb, R. F., Toxic effects of desoxycorticosterone esters in dogs. Science, 1939, 90, 496.

11. Miller, H. C., and Darrow, D. C., Relation of serum and muscle electrolyte, particularly potassium, to voluntary exercise. Am. J. Physiol., 1941, 132, 801.

12. Ingle, D. J., Nilson, H. W., and Kendall, E. C., The effect of cortin on the concentrations of some constituents of the blood of adrenalectomized rats. Am. J. Physiol., 1937, 118, 302.

13. Wells, B. B., and Kendall, E. C., A qualitative difference in the effects of compounds separated from the adrenal cortex on distribution of electrolytes and on atrophy of the adrenal and thymus glands of rats. Proc. Staff Meet., Mayo Clin., 1940, 15, 133.

14. Long, C. N. H., Katzin, B., and Fry, E. G., The adrenal cortex and carbohydrate metabolism. Endocrinology, 1940, 26, 309.

15. Fenn, W. O., The deposition of potassium and phosphate with glycogen in rat livers. J. Biol. Chem., 1939, 128, 297.

16. Durlacher, S., and Darrow, D. C. (To be published.) 